\title{
USO DA CLOREXIDINA COMO AGENTE PREVENTIVO E TERAPÊUTICO NA ODONTOLOGIA.
}

\section{CHLORHEXIDINE USE AS A PREVENTIVE AND THERAPEUTIC AGENT IN DENTISTRY.}

\author{
Sandra Regina Hortense* \\ Érica da Silva Carvalho** \\ Fábio Silva de Carvalho"** \\ Ricardo Pianta Rodrigues da Silva** \\ José Roberto de Magalhães Bastos**** \\ Roosevelt da Silva Bastos ${ }^{* * * *}$
}

\begin{abstract}
RESUMO
A clorexidina é um antimicrobiano sintético que apresenta alto nível de atividade sem, no entanto, ter os efeitos secundários que a maioria dos antimicrobianos apresenta. Pequenas concentrações de sais de clorexidina são geralmente suficientes para inibir o processo reprodutivo ou exterminar a maioria dos microrganismos, além do que, sendo praticamente isenta de toxicidade e efeitos corrosivos, proporciona extrema segurança no seu emprego. O conhecimento das propriedades e o uso da clorexidina permitem ao cirurgião-dentista desenvolver suas atividades com segurança, voltadas à prevenção e ao tratamento de doenças, além de minimizar os riscos de infecção cruzada à equipe odontológica e ao paciente.

Descritores: Odontologia preventiva - Clorexidina - Antiinfecciosos locais.
\end{abstract}

\section{ABSTRACT}

The chlorhexidine is a synthetic antimicrobial agent that has a high level of activity without having side effects that most of antimicrobial present. Small concentrations of chlorhexidine salts are usually sufficient to inhibit the reproductive process or exterminate the most of microorganisms, in addition to that, being free of toxicity and corrosive effects, it provides extreme security in its use. The knowledge of properties and use of chlorhexidine allows dentists to develop their activities in safety and direct to the prevention and treatment of diseases, and minimize the risk of cross infection to dentistry staff and patient.

Descriptors: Preventive Dentistry - Chlorhexidine - Anti-infective agents, local.

\footnotetext{
* Mestranda em Ciências Odontológicas Aplicadas, área de concentração Saúde Coletiva pela Faculdade de Odontologia de Baurú - FOB-USP ** Mestranda em Ciências Odontológicas Aplicadas, área de concentração Saúde Coletiva pela Faculdade de Odontologia de Baurú - FOB-USP *** Doutorando em Ciências Odontológicas Aplicadas, área de concentração Saúde Coletiva pela Faculdade de Odontologia de Baurú - FOB-USP

**** Coordenador da Pós-Graduação em Ciências Odontológicas Aplicadas, àrea de Concentração Saúde Coletiva da Faculdade de Odontologia de Baurú FOB-USP, Professor Titular do Departamento de Odontopediatria,Ortodontia e Saúde Coletiva, FOB-USP

***** Professor Doutor do Departamento de Odontopediatria, Ortodontia em Saúde Coletiva da Faculdade de Odontologia de Baurú - FOB-USP
} 


\section{N T RO DUÇÃ O}

A placa bacteriana é constituída de 70 a $80 \%$ por microrganismos e $30 \%$ por elementos não microbianos, como, por exemplo, polissacarídeos, mucina salivar, detritos alimentares, leucócitos, enzimas, sais minerais, proteínas e células epiteliais descamadas Cauduro Neto 1978 A partir do momento que a placa dental foi considerada o fator causal principal da cárie e de doenças periodontais, é de suma importância o seu controle e prevenção para diminuir a incidência dessas doenças bucais.

Segundo Lindhe, a resposta à placa varia consideravelmente entre as pessoas e, para prevenir o desenvolvimento da doença periodontal, as medidas de higiene devem visar à inibição da formação da placa ou, quando não for possível, à redução da quantidade de placa formada em concentrações tais que não se desenvolva doença inflamatória destrutiva Lendhe 1992.

A clorexidina, dentre os antissépticos de uso oral, é um dos agentes antimicrobianos mais potentes e estudados; é altamente eficaz e em geral utilizada como padrão em relação à potência de outros agentes.

Löe, em seus trabalhos clínicos, provou que com o uso repetido da solução de clorexidina, o número de microrganismos aeróbicos e anaeróbicos na saliva foi reduzido em $80-90 \%$. Segundo tais estudos, com uso prolongado, o número de microrganismos salivares (aeróbicos, anaeróbicos e estreptococos) diminuiu de 50 a $90 \%$ e nenhum crescimento de bactérias entéricas ou leveduras foi encontrado, demonstrando que a clorexidina mostrou uma potente atividade fungicida na cavidade oral e, após o seu uso na forma de colutório, por seis meses, amostras de placa mostraram uma redução de 54 a 97\% de bactérias aeróbicas e anaeróbicas $\operatorname{Loe}^{3}$ 1973.

A FDA (Food and Drug Administration) e a ADA (American Dental Association) autorizaram o uso da clorexidina como agente efetivo para controle de placa, baseando-se em suas propriedades antiplaca e no combate à gengivite Carranza e Newman ${ }^{4} 1997$.

Na Odontologia clínica, a clorexidina é utilizada para limpar campos operatórios, desinfetar canais radiculares, inibir a formação da placa, cáries e gengivite. Outra propriedade importante é a sua capacidade de adsorção no esmalte dos dentes e na mucina salivar, com posterior liberação, exercendo assim um efeito residual.

Este artigo tem como objetivo orientar profissionais da área odontológica quanto ao uso e mecanismo de ação da clorexidina na prevenção e tratamento de doenças bucais.

\section{REVISÃO DA LITERATURA}

\section{Composição da clorexidina}

A clorexidina é um composto que, na sua estrutura, contém dois anéis clorofenólicos e dois grupos bis-biguanida, ligados simetricamente por cadeias de hexametilenica. Essa bis-biguanida é uma base forte, carregada positivamente, praticamente insolúvel em água. Por isso, seu uso em Odontologia é preconizado em forma de sal digluconato, proporcionando-se maior solubilidade à substância Araujo et al. ${ }^{5}$ 2001.

\section{Propriedades da clorexidina}

Substantividade (retentividade): é a capacidade de o produto permanecer retido no local de ação (superfície dental, gengiva e mucosa bucal) ativo, sendo liberado lentamente, evitando-se, assim, que seu efeito seja rapidamente neutralizado pelo fluxo salivar. No tratamento de infecções causadas pela placa dental, a substantividade do agente antimicrobiano é muito importante, uma vez que os agentes necessitam de certo tempo de contato para inibir ou matar um microrganismo.

Estudo realizado por Sinnes et al. constatou que, em cada bochecho feito, $3 \%$ da clorexidina é deglutida, $67 \%$ é expectorada e 30\% fica retida ou adsorvida à película adquirida, às proteínas salivares e à mucosa bucal Sinnes et al. ${ }^{6} 1976$.

\section{Eficácia}

A clorexidina tem se mostrado um efetivo agente antimicrobiano no tratamento de gengivite, dispersor da placa já formada e inibidor da recolonização da placa bacteriana Cury et al. ${ }^{7}$ 2000. Essa ação pode ser atribuída a uma redução do nú-
HORTENSE SR, CARVALHO ES, CARVALHO FS, SILVA RPR,

BASTOS JRM, BASTOS RS.

USO DA CLOREXIDINA COMO AGENTE PREVENTIVO E TERAPÊUTICO NA ODONTOLOGIA.

\section{9}

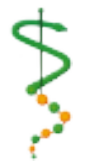

REVISTA DE ODONTOLOGIA DA UN I VERS I DADE CidAdE DE São PAULO

2010; 22(2): 178-84, MAI-AGO 
HORTENSE SR,

CARVALHO ES,

CARVALHO FS,

SILVA RPR,

BASTOS JRM,

BASTOS RS.

USO DA

CLOREXIDINA

COMO AGENTE

PREVENTIVO E

TERAPÊUTICO NA

ODONTOLOGIA.

$180 \ldots$

REVISTA DE

ODONTOLOGIA DA

UNIVERSIDADE

CIDADE DE SÃO

PAULO

$2010 ; 22(2):$

$178-84$, MAI-AGO mero de bactérias na saliva, evitando-se o desencadear do quadro inflamatório da gengivite Schiott et al. ${ }^{8} 1976$.

Desenvolvimento de resistência: Um risco potencial com o uso regular de um agente antimicrobiano local é a possibilidade dos microrganismos adquirirem resistência ou ocorrer uma pressão seletiva na microflora oral, resultante da distribuição destes que foram menos sensíveis à clorexidina. Löe revisou vários trabalhos com o uso prolongado da clorexidina (7 semanas, meio ano, 2 anos) mostrando que foram mínimas as alterações de suscetibilidade dos microrganismos orais Löe $^{3} 1973$.

\section{Segurança}

A clorexidina, até o momento, apresentou baixa evidência de toxicidade sistêmica em seres humanos, além de não produzir qualquer resistência apreciável dos microrganismos da boca; também não tem sido associada a quaisquer alterações teratogênicas (Carranza e Newman ${ }^{4}$ 1997). Segundo Sinnes et al. ${ }^{6}$, diversos testes toxicológicos mostraram que a molécula de clorexidina é altamente estável. Quando ingerida, a quase totalidade é eliminada pelas fezes, quantidades mínimas são absorvidas pelo trato intestinal e eliminadas pelas rotas normais (rins e fígado). Não há evidência de formação de para-cloroanilina, perigosa substância cancerígena Sinnes et al. ${ }^{6} 1997$.

\section{Mecanismo de ação da clorexidina}

A clorexidina em baixa concentração é considerada bacteriostática e em alta concentração, bactericida. A clorexidina é adsorvida sobre a hidroxiapatita do esmalte dos dentes, proteínas salivares, placa e macromoléculas ácidas das superfícies orais, devido a sua carga positiva. Através desses locais de retenção, o fármaco é gradualmente liberado por difusão e a concentração na boca é mantida em um nível suficiente para criar um meio bacteriostático por um período prolongado de tempo Vahdaty et al. ${ }^{9} 1993$.

Hugo e Longworth demonstraram que a molécula catiônica (positiva) da clorexidina interage com a bactéria, provavelmente em decorrência da adsorção à pa- rede celular aniônica (negativa), alterando as estruturas da superfície e aumentando a permeabilidade da membrana bacteriana, facilitando a entrada da clorexidina no citoplasma. O equilíbrio osmótico é perdido e, em consequência, ocorre uma precipitação dos constituintes citoplasmáticos, o que impede a reparação da membrana celular, causando a morte da bactéria Hugo e Longworth 1964.

\section{Espectro de ação}

A ação da clorexidina depende da suscetibilidade dos microrganismos, sendo que os gram-positivos apresentam alta suscetibilidade para a clorexidina em relação aos gram-negativos Long et al. ${ }^{11} 1997$. Certas espécies de estreptococos parecem reter uma quantidade adicional de clorexidina em suas cápsulas polissacarídicas extracelulares. Isso pode estar relacionado à alta sensibilidade dos estreptococos orais à clorexidina Gjermo 121978.

\section{Indicações da clorexidina na Odonto-} logia

A clorexidina é uma alternativa na prevenção e no tratamento de doenças bucais, com mínimos efeitos colaterais, baixa toxicidade local e sistêmica e sem alteração da flora local.

$\mathrm{Na}$ Odontologia, a clorexidina atua de forma preventiva na redução da placa bacteriana, como, por exemplo, em deficientes físicos com limitações motoras, em deficientes mentais, em portadores de aparelhos ortodônticos e em pacientes geriátricos. Pode também ser utilizada na redução de infecções cruzadas (incorporada ao hidrocoloide irreversível), de bactérias viáveis em aerossóis gerados em procedimentos profiláticos, na diminuição de bacteremias pós-cirúrgicas antes de procedimentos cirúrgicos ou periodontais, na desinfecção de escovas de dente e de superfícies.

A ação terapêutica da clorexidina tem papel fundamental na diminuição de doenças e agravos à saúde bucal, como no período de cicatrização após cirurgias orais ou periodontais, em terapias de ulcerações aftosas e de estomatite protética, de gengivite úlcero-necrosante aguda, de fraturas de mandíbula e maxila. Deve-se 
salientar o seu uso na profilaxia e tratamento de infecções orais em pacientes com câncer e nos portadores da síndrome da imunodeficiência adquirida (SIDA).

A utilização de clorexidina em próteses contribui para a redução da formação do biofilme e melhora a condição da mucosa do paciente, combatendo a estomatite protética Budtz e Knudsen ${ }^{13}$ 1978. Segundo estudos de Brightman et al. em pacientes ortodônticos com gengivite estabelecida, a combinação de remoção mecânica da placa e o uso da clorexidina a $0,12 \%$ mostraram redução de $64 \%$ no índice de placa, $61 \%$ no índice de gengivite e $77,2 \%$ no de sangramento gengival Brigthman et al. ${ }^{14} 1991$.

\section{Controle da placa}

O controle da placa se dá por meio da sua propriedade antisséptica associada a uma característica importante que é a adsorção (poder de reter na superfície oral e liberar lentamente), assegurando um ambiente antimicrobiano prolongado Carret et al. ${ }^{15}$ 1997, Rolla e Melsen ${ }^{16} 1925$.

Esse poder de adsorção se explica pela interação eletrostática entre grupos carregados negativamente presente na cavidade oral, como dentes e placa (bactérias) e a clorexidina carregada positivamente. Esse processo aumenta a permeabilidade da parede celular, levando à ruptura do citoplasma e causando a morte celular Shioot e Loe ${ }^{17} 1972$.

A placa, retendo a clorexidina, produz uma inibição no desenvolvimento da placa microbiana pelo seu efeito bactericida e bacteriostático. Dessa forma, prevenindo a cárie dentária e a doença periodontal Loe e Schiot ${ }^{18} 1970$.

Aliado ao controle mecânico, o controle químico da placa auxilia os indivíduos que não podem ou não conseguem realizar uma boa higienização a atingirem melhor padrão de saúde bucal Francis et al. ${ }^{19}$ 1987. Kalaga et al. relataram o controle químico da placa com Gluconato de Clorexidina em deficientes Kalagan et al. ${ }^{20}$ 1989; apesar de estar sujeito à pigmentação dos dentes este efeito pode ser diminuído se for usado em forma de gel ao invés de líquido Bellini et al. ${ }^{21} 1980$.

\section{Uso e administração}

A clorexidina em soluções contendo 0,02 a $0,05 \%$ é usada no tratamento de feridas, queimaduras, antisséptico urinário e das mucosas. A clorexidina pode ser introduzida na cavidade oral de várias maneiras.

A) Bochechos: as soluções de 0,12 \% a $0,2 \%$ têm sido as mais usadas por serem reconhecidas como "Padrão Internacional" e terem sido estudadas extensivamente Denardi ${ }^{22}$ 1994. Os bochechos devem durar 1 minuto, duas vezes ao dia, com $15 \mathrm{ml}$, o que é suficiente para prevenir a formação da placa e o desenvolvimento de gengivite superficial, mas não a periodontite estabelecida com bolsas periodontais já formadas. Não devem ser feitos antes das refeições, pois afetam temporariamente a sensação gustativa. Não são recomendados imediatamente antes ou após a escovação com dentifrícios convencionais, devido à competição pelos sítios de retenção.

B) Irrigações: Irrigadores bucais podem representar um veículo ideal para a aplicação de agentes antimicrobianos. Uma aplicação diária de uma solução de clorexidina com concentração de 0,02\% a 0,5\% por 1 minuto pode ser clinicamente benéfica em algumas situações, uma vez que alguns efeitos indesejáveis dependem da concentração Sinnes et al. ${ }^{6} 1997$.

C) Géis: gel a 0,5\% e $1 \%$ é usual e comum, uma vez que requer aplicação com escova de dente ou através de moldeiras, atingindo, assim, toda a superfície dental. Segundo Borer et al. ${ }^{23}$ (1978), é sob a forma de gel que a clorexidina apresenta menor retenção pelas superfícies da cavidade bucal. Assim, como a atividade antiplaca está relacionada com o mecanismo de retenção-liberação do medicamento, supõe-se que, sob essa forma, seja menos efetiva Borer et al..$^{23} 1978$.

D) Dentifrício: na forma de dentifrício, geralmente a 0,6 ou $0,8 \%$, uma aplicação direta nas áreas necessárias. Essa maneira de aplicar pode reduzir os indesejáveis efeitos colaterais observados pelo uso dos bochechos a longo prazo. O uso da clorexidina sob a forma de dentifrícios tem atividade reduzida, uma vez que há competição ou inativação pelos sítios de re-
HORTENSE SR, CARVALHO ES, CARVALHO FS, SILVA RPR, BASTOS JRM, BASTOS RS.

USO DA CLOREXIDINA COMO aGENTE PREVENTIVO E TERAPÊUICO NA ODONTOLOGIA.

. 181

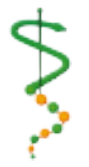

REVISTA DE ODONTOLOGIA DA UN I VERS I DADE Cidade de São PAULO

$2010 ; 22(2)$ : 178-84, MAI-AGO 
HORTENSE SR,

CARVALHO ES,

CARVALHO FS,

SILVA RPR,

BASTOS JRM,

BASTOS RS.

USO DA

CLOREXIDINA

COMO AGENTE

PREVENTIVO E

TERAPÊUTICO NA

ODONTOLOGIA.

$182 \ldots$

REVISTA DE

ODONTOLOGIA DA

UNIVERSIDADE

CIDADE DE SÃO

PAULO

$2010 ; 22(2):$

$178-84$, MAI-AGO tenção entre íons cálcio e os detergentes aniônicos presentes em suas formulações Pinheiro et al. ${ }^{24} 1985$.

E) Spray: é considerado um método de fácil aplicação, porém a sua eficiência depende da habilidade do operador em atingir todos os locais, assim como a dose empregada Denardi'22 1994.

F) Goma de mascar: sua vantagem é que fica retida na cavidade oral por um período de tempo mais prolongado em comparação com os outros métodos, porém cuidados devem ser tomados com as concentrações da clorexidina e do edulcorante utilizado na formulação Pinheiro et al. ${ }^{24} 1985$.

Takeuchi et al. observaram menor acúmulo de bactérias na placa, devido ao uso de verniz à base de clorexidina associada ao flúor, sendo que o desenvolvimento do biofilme foi inibido pelo verniz Takeuchi et al. ${ }^{25} 2007$.

\section{Prevenindo infecções}

O controle da infecção cruzada e a biossegurança são temas de grande importância para a prática odontológica e vêm despertando nos últimos anos maior interesse em virtude, principalmente, do avanço da AIDS Bastos et al. ${ }^{26}$ 2004. A prevenção da infecção cruzada é parte fundamental na conduta prática de um tratamento odontológico, sendo um dos procedimentos fundamentais para manter a biossegurança nos consultórios odontológicos a realização da desinfecção de superfícies Fantinato et al. ${ }^{27} 1994$.

Outra preocupação é evitar a ocorrência de infecção cruzada entre consultório odontológico e laboratório de prótese, veiculada através de moldes contaminados. A ADA anunciou que toda superfície contaminada ou que entre em contato com fluidos corporais humanos deve ser desinfetada Scaraneto et al. ${ }^{28} 2004$. A clorexidina, incorporada aos hidrocoloides irreversíveis, tem efeito antibacteriano; há uma inibição do crescimento de bactéria da saliva pelo alginato com clorexidina, o que se constitui em opção para contro- le de infecções cruzadas em consultórios odontológicos e laboratórios de próteses.

Deve-se salientar a importância da higienização das escovas de dente, pois diversos fatores como a umidade e a disponibilidade de nutrientes as transformam em nichos para a proliferação de microrganismos. Segundo constatado num estudo in vitro sobre descontaminação de escovas contaminadas com Streptococcus mutans Soares et al. ${ }^{29} 2007$, a clorexidina a $0,12 \%$ inibiu totalmente o crescimento do mutans Macari et al. ${ }^{30}$ 2000, Sanches et al. ${ }^{31} 2001$.

O controle e a minimização de microrganismos contidos no aerossol são de grande importância para a saúde da equipe odontológica. Os aerossóis permanecem no ar ao menos por 10 minutos após procedimentos odontológicos e são detectados nas superfícies a $60 \mathrm{~cm}$ da boca do paciente Benthey et al. ${ }^{32} 1994$.

Segundo Grenier, os aerossóis produzidos durante tratamento odontológico contêm bactérias oportunistas que devem ser consideradas perigosas para pacientes com comprometimento imunológico, e é grande o risco de transmissão dessas doenças contagiosas durante os procedimentos odontológicos Grenier ${ }^{33} 1995$. Miller associou esses aerossóis com infecções respiratórias, oftálmicas e infecções na pele, tuberculose e hepatite B Miller ${ }^{34}$ 1976. Uma das vias de transmissão é a aerolização, com peça de mão Logothetis et al. ${ }^{35}$ 1988, raspador de ultrassom Trenter e Walmsley $^{36} 2003$ e jato de bicarbonato de sódio que são usados durante procedimentos clínicos. O nível de contaminação pode ser reduzido significativamente com bochecho prévio de clorexidina a $0.12 \%$ por um minuto Logothetis et al. ${ }^{37} 1995$.

\section{CONSIDERAÇÕES FINAIS}

O conhecimento das propriedades e o uso da clorexidina permitem ao cirurgiãodentista desenvolver suas atividades com segurança, voltadas à prevenção e ao tratamento de doenças, além de minimizar os riscos de infecção cruzada à equipe odontológica e ao paciente. 
1. Cauduro Neto R. Estudo comparativo entre agentes químicos antiplaca:avaliação das pesquisas. RGO. 1978 jan-mar;26(1):55-63.

2. Lindhe J. Tratado de Periodontologia Clínica. 2 ed. Rio de Janeiro: Guanabara; 1992.

3. Löe H. Does Chlorhexidine have a place in the prophylaxis of dental diseases? J Periodont Res.1973; 12: 93-9.

4. Carranza JR, Newman MG. Periodontia clínica. 8 ed. Rio de Janeiro: Guanabara Koogan; 1997.

5. Araujo MTB, Araujo RPC, Campos EJ. Estudo in vitro e in vivo da atividade bactericida da clorexidina 0,12 por cento e a 0,2 por cento e dos produtos farmacológicos Listerine e Duplax. Rev Odonto Ciênc. 2001 mai-ago;16(33):187-200.

6. Sinnes EP et al. Controle químico da placa bacteriana. In: Lascala NT. Prevenção na Clínica Odontológica: promoção da saúde bucal. São Paulo: Artes Médicas: 1997. p.174-185.

7. Cury JA Rocha EP, Koo H, et al. Effect of saccharin on antibacterial activity of chlorhexidine gel. Braz Dent J. 2000;11(1):29-34.

8. Schiott CR, Briner W, Loe H. Two years oral use of chlorhexidine in man. II. The effect on the salivary bacterial flora. J Periodontal Res.1976 Jun;11(3):145-152.

9. Vahdaty A, Pitt Ford TR, Wilson RF. Efficacy of chlorhexidine in disinfecting dentinal tubules in vitro. Endod Dent Traumatol.1993 Dec; 9(6): 243-8.

10. Hugo WB, Longworth AR. Some aspects of the mode of action of chlorhexidine action. Pharm Pharmacol. 1964 Oct;16:655-62.

11. Lang NP, Mombelli A, Tonetti MS, Brägger U, Hämmerle CH. Clinical trials on therapies for peri-implant infections. Ann Periodontol. 1997 Mar; 2(1): 343-56.

12. Gjermo, PA. Clorhexidina na prática odontológica. RGO.1978 jan-mar; 26 (1): 2226.

13. Budtz E, Knudsen AM. Chlorexidine gel and Steradent employed in cleaning dentures. Acta Odontol Scand. 1978; 36: 83-7.

14. Brigthman LJ, Terezhalmy GT, Greenwell H et al.The Effects of a $0.12 \%$ chlorhexidine gluconate mouthrinse on orthodontic patients aged 11 vthrough 17 with established gingivitis. Amer J Orthdont Dentofac Orthop. 1991 Oct; 100(4): 324-29.

15. Carret L, Reverdy ME, Lafforgue C, et al. Effects of chlorhexidine on intact skin following a single applicacion. Pathol Biol. 1997 Nov; 45(9):737-40.

16. Rolla G, Melsen B. On the mechanism of plaque inhibition by chlorhexidine. J Dent Res. 1975;54(3):57-62.

17. Schiott CR, Loe H. The sensitivity of oral streptococci to chlorhexidine. J Periodont Res. 1972; 7(2): 192-4.

18. Loe H, Shioot CR. The effect of mouthrinse and topical applicacions of chlorhexidine on the development of plaque and gingivitis in man. J Periodotol Res.1970 Apr; 5(2): 79-83.

19. Francis JR, Hunter B, Addy MA.Comparison of three delivery methods of chlorhexidine in handicapped children effects on plaque, gingivitis and toothstaining. J Periodontol. 1987 Jul;58(7):451-55.

CARVALHO ES

CARVALHO FS,

SILVA RPR,

BASTOS JRM,

BASTOS RS.

USO DA

CLOREXIDINA

COMO AGENTE

PREVENTIVO E

TERAPÊUTICO NA

ODONTOLOGIA.

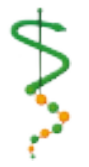

REVISTA DE ODONTOLOGIA DA UNI VERS I DADE Cidade de São PAULO

2010; 22(2):

178-84, MAI-AGO 
HORTENSE SR,

CARVALHO ES,

CARVALHO FS,

SILVA RPR,

BASTOS JRM,

BASTOS RS.

USO DA

CLOREXIDINA

COMO AGENTE

PREVENTIVO E

TERAPÊUTICO NA

ODONTOLOGIA.

\section{4}

REVISTA DE ODONTOLOGIA DA UNIVERSIDADE CIDADE DE SÃO PAULO

2010; 22(2): $178-84$, MAI-AGO
20. Kalaga A, Addy M, Hunter B. The use of $0.2 \%$ chlorhexidine spray as an adjunct to oral hygiene and gingival health in physically and mentally handicapped adults. J Periodontol.1989 Jul; 60(7):381-5.

21. Bellini HT, Moraes FRB, Ferraz DP, Moro Filho D, Lima ACP. Uso da Clorexidina no controle da placa e da gengivite. Rev Ass Paul Cirurg Dent. 1980 jul-ago; 34(4):27682.

22. Denardi BB. O uso da clorexidina na prática odontológica. Revista da APCD. 1994 mar; 48(2):1279-85.

23. Borer KT et al. Increased serum growth hormone and somatic growth in exercising adult hamsters. The American journal of physiology. 1978 Jun; 234(6): E611-6.

24. Pinheiro CE, Vono AZ, Pavarini AB et al. Goma de mascar contendo Clorhexidina: avaliação de sua capacidade antiplaca e anticárie. RGO.1985 jan-mar; 33(1): 6770.

25. Takeuchi Y, Guggenheim B, Filieri A, Baehni P. Effect of chlorhexidine/thymol and fluoride varnishes on dental biofilm formation in vitro. Eur J Oral Sci. 2007 Dec; 115(6): 468-72.

26. Bastos JRM, Bardal PAP, Castro RFM, et al. Chlorhexidine use at dentistry.Saluvista. 2004;23(1):15-24.

27. Fantinato $V$ et al. Esterilização. In: Fantino A. Manual de esterilização e desinfecção em odontologia. São Paulo: Santos; 1994. p. 15-19.

28. Scaranelo RM, Bombonatti PE, Rister RP, et al. Efeito de soluções desinfetantes cloradas na resistência à compressão e dureza superficial de gesso. PCL. 2004 marabr;6(30):159-165.

29. Soares DGS, Oliveira CB, Leal C, Drumondi MRS, Padilha WWN. Atividade antibacteriana in vitro da tintura de aroeira na descontaminação de escovas dentais contaminadas pelo S. Mutans. Pesq .Bras Clin Integr. 2007 set-dez; 7(3): 253-257.

30. Macari SM, Nelson Filho P, Ito IY, Faria G.Assed S. As escovas dentais devem ser desinfetadas após a sua utilização? [Trabalho de Conclusão de Curso]. Ribeirão Preto (SP): Faculdade de Odontologia. Universidade de São Paulo; 2000.

31. Sanches MH, Peres SHCS, Peres AS, Bastos JRM. Descontaminação das escovas dentais por imersão em soluções antissépticas. RGO. 2001 jul-set; 49(3):167-71.

32. Benthey CD, Burkehart NW, Crawford JJ. Evaluating spatter and aerosol contamination during dental procedures. J Am Assoc. 1994 May;125(5):579-84.

33. Grenier D. Quantitative analysis of bactérial aerosols in two different dental clinic environments. Appl Environ Microbiol. 1995 Aug; 61(8): 3165-8.

34. Miller RL. Generation of airborne infection by high speed dental equipment. J Am Soc Prev Dent. 1976 May-Jun; 6(3): 14-7.

35. Logothetis DD, Gross KBW, Eberhart A, Drisco C. Bacterial airborne contamination with an air-polishing device. Gen Dent. 1988 Nov-Dec; 36(6): 496-9.

36. Trenter SC, Walmsley AD. Ultrasonic dental scaler: associated hazards. J Clin Periodontol. 2003 Feb; 30(2): 95-101.

37. Logothetis DD, Welles JM. Reducing bacterial aerosol contamination with a chlorhexidine gluconate prerinse. J Am Dent Assoc. 1995 Dec; 126(12): 1634-9.

Recebido em: 23/11/2009

Aceito em: 16/03/2010 